\title{
Transformation Optics and Invisibility Cloaking
}

\author{
Young Chul JuN* . In Cheol SEO • Sung Chan LiM \\ Department of Physics, Inha University, Incheon 402-751, Korea
}

(Received 26 September 2014 : revised 27 October 2014 : accepted 28 October 2014)

\begin{abstract}
Transformation Optics (TO) enables arbitrary control of electromagnetic waves via spatiallytailored effective material parameters. TO is revolutionizing our understanding of how to control the flow of light. It not only revolutionizes the fundamental physics of light-matter interactions, but also implements totally new optical functions. For instance, it enables highly unusual optical functions that may otherwise be almost impossible or difficult to obtain, such as invisibility cloaking, illusion optics, optical black holes, lossless waveguide bends, etc. The basic idea is that a mathematical transformation of space can be represented by a change in the material effective parameters. TO provides an elegant way to control the flow of light, but it usually requires extreme material parameters that can be too complicated to realize or can be implemented only through resonant metallic metamaterials. However, meaningful advances have been made recently to resolve these difficulties. In this review article, we introduce the concepts of TO and explore recent developments. There has been a plethora of new ideas in this field, but large opportunities for both fundamental and applied research are still waiting for us.
\end{abstract}

PACS numbers: 42.15.Eq, 42.79.-e, 42.70.-a

Keywords: Transformation optics, Invisibility cloaking, Metamaterials, Nano-optics

\section{변환광학과 투명망토}

\author{
전영철* · 서인철 · 임성찬
}

인하대학교 물리학과, 인천 402-751

(2014년 9월 26일 받음, 2014년 10월 27일 수정본 받음, 2014년 10월 28일 게재 확정)

변환광학은 공간상의 물질상수 (즉 유전율, 투과율, 굴절률) 분포를 조절하여 빛의 흐름을 임의로 조절하려는 연구분야이다. 이는 나노광학 연구의 새로운 패러다임이 되고 있으며, 기초연구뿐 아니 라 여러 응용 가능성도 제시되고 있다. 가령, 투명망토, 환영광학, 광 블랙홀, 손실이 없는 곡선형 도 파로 등 다른 방법으로는 구현이 거의 불가능한 것들을 가능하게 하고 있다. 변환광학은 많은 새로 운 가능성을 제시해 주나, 복잡한 물질상수 분포를 구현하기 어렵다는 단점도 있다. 하지만 최근에 이런 문제들을 극복하려는 의미 있는 연구들이 진행되어 왔다. 본 총설논문에서는 변환광학의 개념 을 소개하고 수학적 기초를 설명한다. 특히 투명망토를 구현하기 위한 물질상수 분포를 유도하고 실 험으로 구현한 예들을 알아 본다. 또한 변환광학을 이용한 다른 응용기술과 광학소자들을 소개하고 최신 연구동향을 살펴 보고자 한다.

PACS numbers: 42.15.Eq, 42.79.-e, 42.70.-a

Keywords: 변환광학, 투명망토, 메타물질, 나노광학 


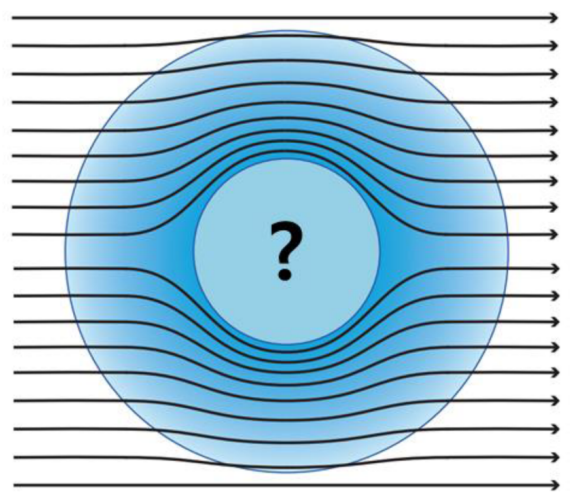

Fig. 1. (Color online) An invisibility cloak can be realized by spatially tailoring effective material parameters. The field is excluded from the center region and emerges from the cloaking sphere undisturbed.

\section{I. 서 론}

투명인간이나 투명망토 (Invisibility cloak)는 오랫동 안 소설이나 영화의 단골 소재로 등장하였다. 이는 상상 력을 자극하고 이야기를 더욱 풍성하게 만드는 장치로 활용되어 왔다. 하지만 이들 소재는 더 이상 공상과학 소 설이나 영화의 영역이 아닌 현실이 되어 가고 있다. 가 령 Fig. 1과 같이 어떤 미지의 물체를 구형 껍질로 둘러 싸고 들어오는 빛이 산란되거나 반사되지 않고 휘어 가 게 할 수 있다면 우리는 이 물체의 존재 여부를 알 수 없 다. 즉 이 구형 껍질은 투명망토가 되는 셈이다. 빛은 직 진한다는 것이 우리가 보통 가지고 있는 상식이므로 이 런 구형 껍질을 실제로 만들 수 있을지 의아해 할 수 있 다. 하지만 빛이 통과하는 매질의 굴절률이 연속적으로 변한다면 빛도 자연스럽게 휠 수 있다.

빛이 이렇게 휘어져 가는 현상은 우리 주변의 자연계 에서도 일어난다. 가령 Fig. 2는 사막에서 볼 수 있는 신 기루 (mirage) 현상을 보여준다. 사막의 뜨거운 햇볕 때 문에 땅 바로 위의 공기는 상층부의 공기보다 더 뜨겁고 밀도가 낮게 된다. 따라서 상층부의 공기보다 굴절률이 낮아져 빛이 휘어지게 된다. Figure 2 에서 보는 것처럼 멀리서 이를 보는 사람은 마치 사막에 물이 있는 것 같 은 신기루를 보게 된다. 비슷한 현상은 여름에 아스팔트 도로 위에서도 종종 목격된다.

굴절률에 따라 빛이 휘는 현상은 우리가 잘 알고 있는 스넬의 법칙에서 쉽게 이해할 수 있다. Figure 3과 같이 여러 층의 물질이 쌓여 있고 각 층의 굴절률이 점점 줄어 든다고 하자. 그러면 스넬의 법칙 $\left(n_{1} \sin \theta_{1}=n_{2} \sin \theta_{2}\right)$ 으 로부터 아래층으로 갈수록 빛의 굴절각은 커져야 함을 알 수 있다. 층 수가 점점 많아지고 굴절률이 연속적으 로 변하게 된다면 빛은 자연스럽게 휘어져 나가야 함

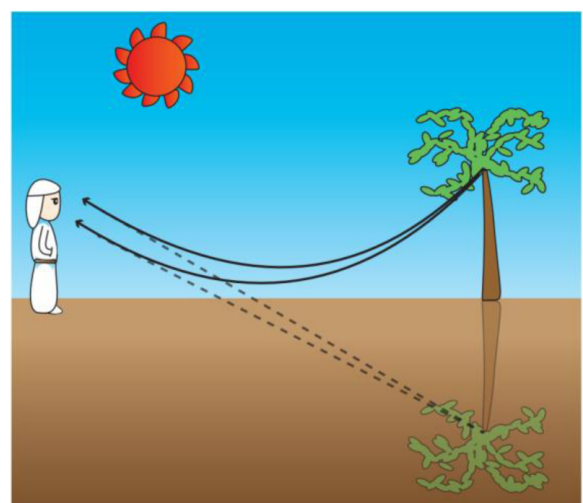

Fig. 2. (Color online) Desert mirage illustrating a curved light path.

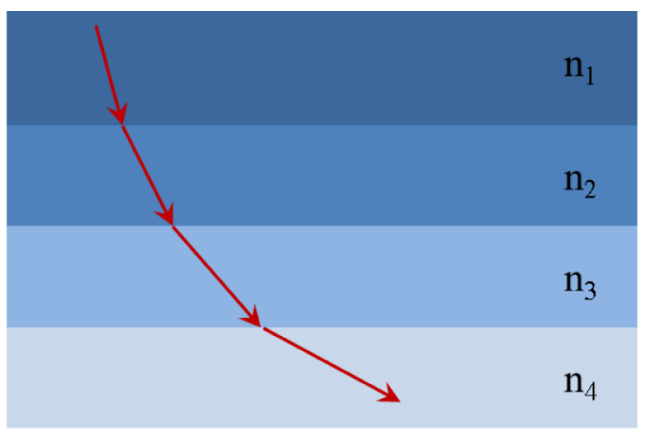

Fig. 3. (Color online) Curved ray path in a multilayer stack with increasing refractive indexes.

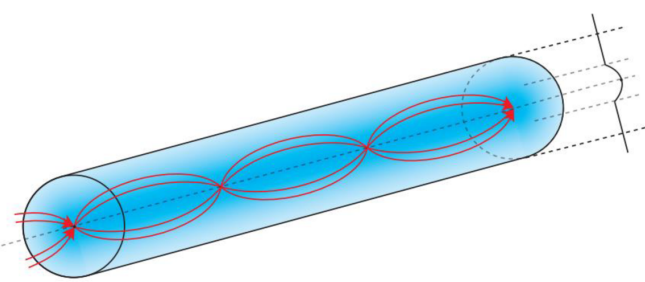

Fig. 4. (Color online) Curved ray path in a gradient index (GRIN) optical fiber. The diagram in the right corner shows the refractive index profile inside the GRIN fiber.

을 알 수 있다. 뜨거운 사막에서 공기의 밀도가 지표면 에 가까울수록 줄어들므로 굴절률도 줄어들게 되고 빛 도 Fig. 2처럼 휘어져야 한다.

사실 휘어져 나가는 빛은 이미 산업계에서도 중요하 게 쓰이고 있다. 가령 광섬유 중 GRIN (gradient index) fiber는 광섬유의 중심부에서 바깥쪽으로 갈수록 굴절률 이 점진적으로 줄어들게 만들어져 있다 (Fig. 4). 광섬 유 제작 시 내부의 불순물 농도를 조절하여 굴절률이 Fig. 4의 오른쪽 끝에 보여지듯이 점진적으로 변하도록 하였다. 광섬유 중심부에서 굴절률이 제일 크고 바깥쪽 으로 갈수록 줄어든다. 불순물의 양을 조절하여 우리가 
원하는 굴절률 분포를 만들 수 있다. 이 GRIN fiber에 서는 빛이 자연스럽게 광섬유 중심 쪽으로 휘게 되며 Fig. 4에 보여지듯이 빛이 주기적으로 다시 만나게 된다. 이는 광섬유 내의 분산 (dispersion)을 줄여주는 효과를 갖게 한다.

따라서 우리가 물질의 굴절률 분포를 잘 조절할 수 있 다면 Fig. 1 과 같이 물체 주위를 빛이 휘어져 가게 하는 투명망토도 만들 수 있게 된다. 이와 같이 물질의 굴절률 분포나 구조를 조절하여 물질 내부에서의 빛의 흐름을 조절하는 분야를 '변환광학' (Transformation Optics)라 고 부른다 [1-10]. '변환'이라는 말이 붙은 이유는 우리 가 원하는 굴절률 분포를 좌표변환을 통해 얻을 수 있기 때문이다. 맥스웰 방정식이 갖는 고유한 좌표변환 특성 을 이용하여 우리가 원하는 빛의 흐름을 얻을 수 있는 물 질상수 (굴절률, 유전율, 투과률 등) 분포를 구할 수 있 다. 변환광학은 이전의 방법으로 구현이 거의 불가능 했 던 광학소자들을 디자인할 수 있게 해 준다. 위에서 언급 한 투명망토가 대표적인 예이며, 다른 광학소자에도 유 용하게 응용될 수 있다 [11-20].

본 총설논문에서는 광학분야의 새로운 디자인 패러다 임으로 관심을 받고 있는 변환광학의 개념을 소개하고 최근 연구동향을 살펴 보고자 한다. 투명망토에 대한 연 구를 중심으로 변환광학의 최신 연구주제들을 살펴보도 록 한다.

\section{II. 변환광학의 수학적 기초}

우선 맥스웰 방정식의 좌표변환 특성을 수학적으로 표 현하고 이를 통해 어떻게 우리가 원하는 물질상수 분포 를 얻을 수 있는지 알아본다 [21-23]. 이 물질상수를 실 제로 구현해 내면 빛의 흐름을 우리가 원하는 대로 조절 할 수 있게 되고 투명망토 및 여러 신개념 광학소자들을 만들 수 있게 된다.

직교좌표계에서 공간상의 다른 좌표로의 변환 $(\vec{r}=$ $\left.(x, y, z) \rightarrow \vec{r}^{\prime}=\left(x^{\prime}, y^{\prime}, z^{\prime}\right)\right)$ 은 아래와 같은 자코비안 (Jacobian) 행렬 $\boldsymbol{A}$ 로 기술된다. 이 행렬은 공간을 얼마 나 잡아 늘리고 돌리는가를 나타낸다.

$$
\boldsymbol{A}=\left[\begin{array}{lll}
\frac{\partial x^{\prime}}{\partial x} & \frac{\partial x^{\prime}}{\partial y} & \frac{\partial x^{\prime}}{\partial z} \\
\frac{\partial y^{\prime}}{\partial x} & \frac{\partial y^{\prime}}{\partial y} & \frac{\partial y^{\prime}}{\partial z} \\
\frac{\partial z^{\prime}}{\partial x} & \frac{\partial z^{\prime}}{\partial y} & \frac{\partial z^{\prime}}{\partial z}
\end{array}\right]
$$

임의의 벡터 함수 $\vec{F}(\vec{r})$ 의 좌표변환은 자코비안 행렬 $\boldsymbol{A}$ 를 사용하여 다음과 같이 쓸 수 있다.

$$
\vec{F}^{\prime}\left(\vec{r}^{\prime}\right)=\left(\boldsymbol{A}^{T}\right)^{-1} \vec{F}(\vec{r}) \text { 또는 } \vec{F}(\vec{r})=\boldsymbol{A}^{T} \vec{F}^{\prime}\left(\vec{r}^{\prime}\right)
$$

임의의 연산자 (operator) $O(\vec{r})$ 의 좌표변환에 대해서 도 아래와 같이 쓸 수 있다.

$$
\begin{aligned}
O^{\prime}\left(\overrightarrow{r^{\prime}}\right) & =\frac{A O(\vec{r}) A^{T}}{\operatorname{det} A} \text { 또는 } \\
O(\vec{r}) & =\operatorname{det} \boldsymbol{A} \cdot \boldsymbol{A}^{-1} O^{\prime}\left(\overrightarrow{r^{\prime}}\right)\left(A^{T}\right)^{-1}
\end{aligned}
$$

맥스웰 방정식은 좌표변환 시 그 형태가 변하지 않음 (form-invariance)이 알려져 있고, 이는 변환광학의 이론 적 토대가 된다. 단일 주파수에 대한 맥스웰 방정식은 아 래와 같다. 여기서 $e^{i \omega t}$ 의 시간의존성과 source-free 영역 을 가정하였다.

$$
\nabla \times \vec{E}=-i \omega \mu \vec{H}, \nabla \times \vec{H}=-i \omega \varepsilon \vec{E}
$$

여기서 $\vec{E}$ 와 $\vec{H}$ 는 각각 전기장과 자기장이다. 물질의 광 학적 특성을 나타내는 유전율 (permittivity) $\varepsilon$ 과 투과 율 (permeability) $\mu$ 는 일반적으로 $3 \times 3$ 텐서 (tensor) 형태로 표현된다. 좌표변환 $\left(\vec{r}=(x, y, z) \rightarrow \vec{r}^{\prime}=\right.$ $\left.\left(x^{\prime}, y^{\prime}, z^{\prime}\right)\right)$ 후 식 (4)는 아래와 같이 표현된다.

$$
\nabla^{\prime} \times \vec{E}^{\prime}=-i \omega \mu^{\prime} \vec{H}^{\prime}, \quad \nabla^{\prime} \times \vec{H}^{\prime}=i \omega \varepsilon^{\prime} \vec{E}^{\prime}
$$

맥스웰 방정식의 전체적인 형태는 바뀌지 않으며, 식 (5)에서 각 연산자와 벡터는 식 $(2),(3)$ 에 따라 변환된 다. 가령 $3 \times 3$ 텐서인 유전율과 투과율은 다음과 같이 변형된다.

$$
\varepsilon^{\prime}=\frac{A \varepsilon A^{T}}{\operatorname{det} A}, \quad \mu^{\prime}=\frac{A \mu A^{T}}{\operatorname{det} A}
$$

좌표변환 후에도 식 (5)와 같이 맥스웰 방정식의 형태가 변하지 않음을 쉽게 확인할 수 있다. 식 (4) 중 패러데이 의 식 $\nabla \times \vec{E}=-i \omega \mu \vec{H}$ 에 대해 이를 확인해 보자. 좌표 변환 시 전기장, 자기장, 투과율은 아래와 같이 변환된 다.

$$
\vec{E}^{\prime}=\left(\boldsymbol{A}^{T}\right)^{-1} \vec{E}, \quad \vec{H}^{\prime}=\left(\boldsymbol{A}^{T}\right)^{-1} \vec{H}, \mu^{\prime}=\frac{A \mu A^{T}}{\operatorname{det} A}
$$

이로부터 다음의 표현식을 얻을 수 있다.

$$
\vec{E}=\boldsymbol{A}^{T} \vec{E}^{\prime}, \vec{H}=\boldsymbol{A}^{T} \vec{H}^{\prime}, \mu=\operatorname{det} \boldsymbol{A} \cdot \boldsymbol{A}^{-1} \mu^{\prime}\left(\boldsymbol{A}^{T}\right)^{-1}
$$

이를 $\nabla \times \vec{E}=-i \omega \mu \vec{H}$ 에 각각 대입해서 정리하면 아래 와 같다.

$$
\frac{A(\nabla \times) A^{T}}{\operatorname{det} A} \vec{E}^{\prime}=-i \omega \mu^{\prime} \vec{H}^{\prime}
$$

여기서 $\nabla^{\prime} \times=\frac{A(\nabla \times) A^{T}}{\operatorname{det} A}$ 이므로, 식 $(9)$ 는 $\nabla^{\prime} \times \vec{E}^{\prime}=$ $-i \omega \mu^{\prime} \vec{H}^{\prime}$ 와 같음을 알 수 있다. 즉 맥스웰 방정식 


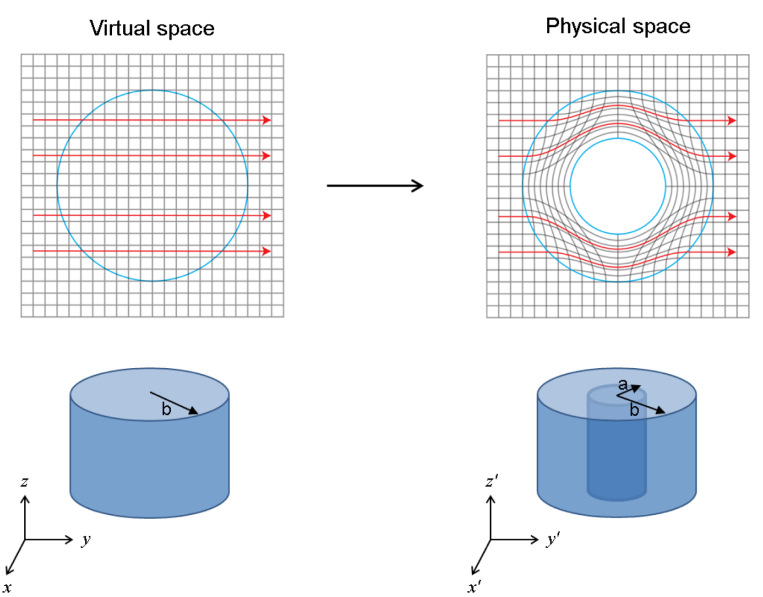

Fig. 5. (Color online) (Upper) An example coordinate transformation describing deformation of ray paths. Ray paths follow the transformed grid lines. (Lower) A cylindrical region of $\mathrm{r}<\mathrm{b}$ in the virtual space $(\mathrm{r}, \theta, \mathrm{z})$ is compressed into a concentric cylindrical shell of a $<$ r' $<$ $\mathrm{b}$ in the physical (i.e., real) space.

이 공간상의 변형에 대해 형태가 바뀌지 않음 (forminvariance)을 실제로 확인할 수 있다.

이는 물리적으로 아주 중요한 의미를 갖는다. 공간의 변형 대신 물질상수가 식 (6)과 같이 변형되어도 빛은 마치 공간이 휜 것처럼 휘어져 나가야 한다는 것을 의미 한다 [3]. 이를 변환광학에서 물질상수 해석 (materials interpretation)이라는 이름으로 불리기도 한다. 이는 투 명망토와 같은 새로운 변환광학 소자를 만드는 데 핵심 적인 기초가 된다. 우리가 원하는 대로 빛의 흐름을 조 절하고자 한다면, 그에 맞는 공간 상의 변형을 먼저 생 각하고 이에 해당하는 물질상수 분포를 식 (6)에 따라 찾 아내면 된다. 그러면 마치 공간이 변형된 것 같은 효과 를 얻을 수 있고, 빛의 흐름도 그에 맞게 변형된다. 결론 적으로 이는 서론에서 애기했던 굴절률 $\left(n=\sqrt{\varepsilon_{r} \mu_{r}}\right)$ 의 연속적인 변화를 통해 빛의 흐름을 조절하는 것과 같은 애기가 된다.

좌표변환을 이용한 변환광학의 예로 원통 형태의 투 명망토를 구현하는 방법에 대해 알아보자. Figure 5 의 윗부분에서처럼 우리가 공간상의 한 점을 부풀려서 속 이 빈 원통형으로 만든다면 그림처럼 좌표계도 변할 것 이다. 이렇게 휘어진 공간상에서는 빛도 휘어져 갈 것 이다. (실제로 중력에 의해 휘어진 공간에서는 빛이 이 에 따라서 휘어지게 된다) 위에서 애기했듯이 이런 공 간상의 변형은 물질상수 분포 $(\varepsilon, \mu)$ 의 변형으로도 표현 가능하다. 왼쪽의 경우를 가상좌표계 $(r, \theta, z)$ 라 하고, 오 른쪽의 경우를 변형된 좌표계 또는 물리적 공간좌표계 $\left(r^{\prime}, \theta^{\prime}, z^{\prime}\right)$ 라 해 보자 (편의상 원통형 좌표계를 사용하여
표시하였다). 가상공간 상에서 속이 채워져 있는 원통 영 역 $r<b$ 에 대해 생각해 보자 (Fig. 5 의 아래부분). 이를 물리적 공간에서의 원통좌표계 $\left(r^{\prime}, \theta^{\prime}, z^{\prime}\right)$ 로 좌표변환 했 을 때, 원통의 중심축 $r=0$ 이 속이 빈 영역 $r^{\prime}<a$ 으로 변환된다고 하자. 그러면 물리적 공간에서는 속이 빈 동 심형 원통 $a<r^{\prime}<b$ 으로 변환되게 되고, 빛도 그림에서 보여지듯이 이 원통영역을 피해 휘어져 가야 한다. 이에 해당하는 물질상수 분포를 식 (6)을 통해 얻으면 원통형 투명망토를 만들 수 있다. 이런 변환은 아래와 같은 좌 표변환을 통해 얻을 수 있다 [24].

$$
r^{\prime}=\left(1-\frac{a}{b}\right) r+a, \theta^{\prime}=\theta, z^{\prime}=z
$$

이는 우리가 원하는 대로 $r=0$ 이 $r^{\prime}=\mathrm{a}$ 가 되게 하고, $r=b$ 이 $r^{\prime}=b$ 가 되게 하는 공간상의 좌표변환이다. 가상 공간은 진공이라고 가정할 수 있으므로 $\varepsilon=\varepsilon_{0}, \mu=\mu_{0}$ 이 다.

$$
\varepsilon^{\prime}=\frac{A \varepsilon A^{T}}{\operatorname{det} A}, \mu^{\prime}=\frac{A \mu A^{T}}{\operatorname{det} A}, \frac{\varepsilon}{\varepsilon_{0}}=\frac{\mu}{\mu_{0}}=\left[\begin{array}{lll}
1 & 0 & 0 \\
0 & 1 & 0 \\
0 & 0 & 1
\end{array}\right]
$$

식 (10)에 해당하는 변환을 원통좌표계에서 자코비안 행 렬 $\mathbf{A}$ 로 표현하면 다음과 같다.

$$
\mathbf{A}=\left[\begin{array}{ccc}
\frac{\partial r^{\prime}}{\partial r} & \frac{\partial r^{\prime}}{r \partial \theta} & 0 \\
\frac{r^{\prime} \partial \theta^{\prime}}{\partial r} & \frac{r^{\prime} \partial \theta^{\prime}}{r \partial \theta} & 0 \\
0 & 0 & 1
\end{array}\right]=\left[\begin{array}{ccc}
1-\frac{a}{b} & 0 & 0 \\
0 & \frac{r^{\prime}}{r} & 0 \\
0 & 0 & 1
\end{array}\right]
$$

위의 식들을 사용해서 물리적 공간 $\left(a<r^{\prime}<b\right)$ 에서 원통형 투명망토를 구현하는 물질상수를 구해 보면 다 음과 같다 $[24,27]$.

$$
\begin{aligned}
& \varepsilon_{r}^{\prime} / \varepsilon_{0}=\mu_{r}^{\prime} / \mu_{0}=\frac{r^{\prime}-a}{r^{\prime}} \\
& \varepsilon_{\theta}^{\prime} / \varepsilon_{0}=\mu_{\theta}^{\prime} / \mu_{0}=\frac{r^{\prime}}{r^{\prime}-a} \\
& \varepsilon_{z}^{\prime} / \varepsilon_{0}=\mu_{z}^{\prime} / \mu_{0}=\left(\frac{b}{b-a}\right)^{2} \cdot \frac{r^{\prime}-a}{r^{\prime}}
\end{aligned}
$$

비슷한 좌표변환 방법으로 원통이 아닌 구형 투명망 토에 대한 다음의 물질상수 조건도 찾을 수 있다 [1] $(a<$ $\left.r^{\prime}<b\right)$.

$$
\begin{aligned}
& \varepsilon_{r}^{\prime} / \varepsilon_{0}=\mu_{r}^{\prime} / \mu_{0}=\frac{b}{b-a} \cdot\left(\frac{r^{\prime}-a}{r^{\prime}}\right)^{2} \\
& \varepsilon_{\theta}^{\prime} / \varepsilon_{0}=\mu_{\theta}^{\prime} / \mu_{0}=\frac{b}{b-a} \\
& \varepsilon_{\phi}^{\prime} / \varepsilon_{0}=\mu_{\phi}^{\prime} / \mu_{0}=\frac{b}{b-a}
\end{aligned}
$$




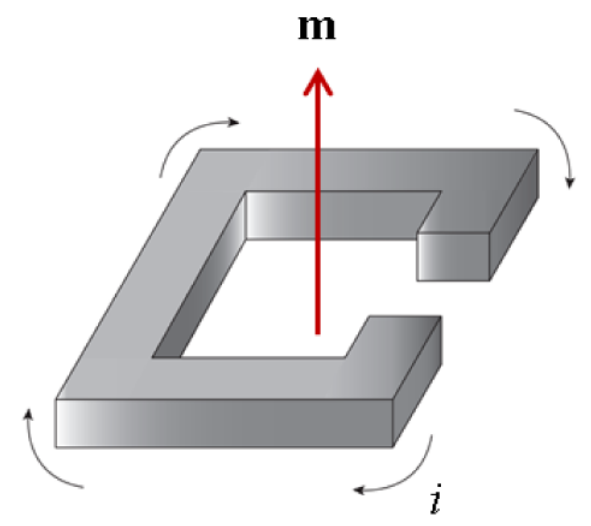

Fig. 6. (Color online) Schematic of a split-ring resonator (SRR).

\section{III. 투명망토의 구현}

1990 년대 이후로 빛의 흐름을 임의로 조절하는 광학 나노구조에 대한 관심이 크게 늘었다. 광결정 (Photonic Crystals)은 유전체를 빛의 파장 스케일에서 패터닝해서 유전상수의 주기적인 변화를 얻는 구조이다 [25]. 이런 구조에서는 반도체 결정이 전자의 흐름에 대해 밴드갭 을 갖듯이 빛에 대해 광밴드갭을 가질 수 있다. 광밴드 구조를 조절하여 빛의 흐름을 조절하고 새로운 광학소 자들을 구현할 수 있다. 빛의 흐름을 조절하는 방법을 제시한다는 면에서 광결정과 관련이 있으나, 변환광학 은 빛의 파장보다도 훨씬 작은 영역에서 물질의 구조 등 을 디자인하여 유효 물질상수 (유전율, 투과율)를 조절한 다는 차이점을 가진다. 변환광학은 기본적으로 광학 메 타물질 [26-30]을 사용하여 원하는 물질 상수분포를 얻 게 된다. 광학 메타물질은 사람들이 subwavelength 영역 에서 물질을 디자인하여 새로운 물질 특성을 얻는 구조 로, 보통 표면 플라즈몬 공명체 같은 나노 금속구조를 기 본 단위로 하고 있다 $[31,32]$. 이 기본 단위를 메타원자 (meta-atom)라고 부르기도 한다. 이 메타원자 각각은 높 은 주파수 영역대에서 자기공명을 가지므로 우리가 원 하는 유전율, 투과율을 구현하는 데 쓰일 수 있다. 메타 물질은 이런 메타원자들을 반복적으로 배열해서 만들어 진다.

자연상에 존재하는 물질들은 $\mathrm{GHz}$ 이상의 초고주파 영 역에서는 투과율 $\mu$ 의 변화가 거의 없다. 하지만 최근에 개발된 메타물질 구조를 사용하여 높은 주파수의 전자 기파 영역대에서도 유전율 $\varepsilon$ 과 투과율 $\mu$ 둘 다를 조절하 는 것이 가능하다. Figure 6과 같은 Split-ring resonator $(\mathrm{SRR})$ 은 자기공명을 갖는 대표적인 메타원자의 예이다

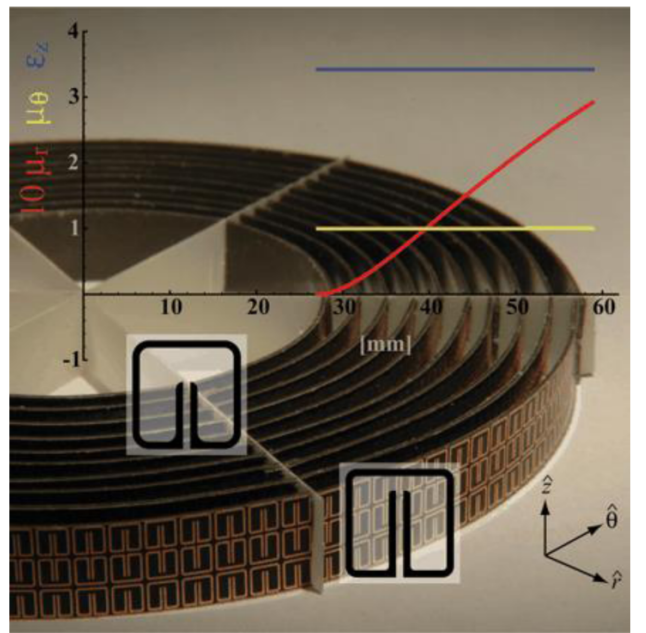

Fig. 7. (Color online) Cylindrical cloaking device at a microwave frequency with a plot of the material parameters that are implemented. $\mu_{r}$ (red line) is multiplied by a factor of 10 for clarity. $\mu_{\theta}$ (yellow line) has the constant value 1. $\epsilon_{z}$ (blue line) has the constant value 3.42 . The SRRs of the innermost cylinder and the outermost cylinder are shown in expanded schematic form (square insets). Reprinted from Ref. [24] with permission.

[33]. 금속의 유전상수는 음이므로, 금속과 유전체를 잘 혼합하여 우리가 필요로 하는 유효 유전율을 만들 수 있 다. 또한 SRR 같은 자기공명체를 사용해서 공명 주파수 근처에서 유효 투과율이 음이 되거나 큰 양의 값을 갖도 록 조절할 수 있다. 이 둘을 잘 혼합하고 조절하여 우리 가 원하는 물질 상수 분포를 얻어내는 것이 투명망토를 포함한 모든 변환광학 연구의 핵심이라 할 수 있다.

식 (6)에 주어진 물질상수 분포를 만드는 게 쉬운 일 은 아니나, 원통형 투명망토는 마이크로파 영역에서 실 험으로 구현된 바 있다 (Fig. 7). 메타물질 구조를 좀 더 단순화하기 위해 $\mathrm{TE}$ 편광파에 대한 원통형 투명망토를 생각해 보자. 이 경우 물질상수는 $\varepsilon_{z}^{\prime}, \mu_{r}^{\prime}, \mu_{\theta}^{\prime}$ 세 개의 성 분만이 필요하다. 또, $\mathrm{TE}$ 편광파에 대해 $\mu_{\theta}^{\prime}=1$ 이 되도 록 임의로 잡을 수 있다 [24]. 그러면, 원통형 투명망토 에 필요한 물질상수는 다음과 같이 된다 $\left(a<r^{\prime}<b\right)$.

$$
\mu_{r}^{\prime} / \mu_{0}=\left(\frac{r^{\prime}-a}{r^{\prime}}\right)^{2}, \mu_{\theta}^{\prime} / \mu_{0}=1, \varepsilon_{z}^{\prime} / \varepsilon_{0}=\left(\frac{b}{b-a}\right)^{2}
$$

이 경우 $\varepsilon_{z}^{\prime}$ 는 1 보다 큰 상수이고, 투과율 성분 중 $\mu_{r}^{\prime}$ 만 이 반경 (radial) 방향으로 변화하게 되어 물질상수의 구 현이 훨씬 더 용이해 진다. Figure 7은 이 물질상수를 실 험으로 구현한 투명망토 구조이다. SRR 구조는 들어오 는 전자기파에 반응하여 자기공명을 나타낸다 (Fig. 6). $\mathrm{SRR}$ 단위 셀의 구조와 밀도에 변화를 줌으로써 원하는 투과율 분포 $\mu_{r}$ 을 얻을 수 있다. 이 때 $\varepsilon_{z}^{\prime}$ 는 원하는 상수 
(a)

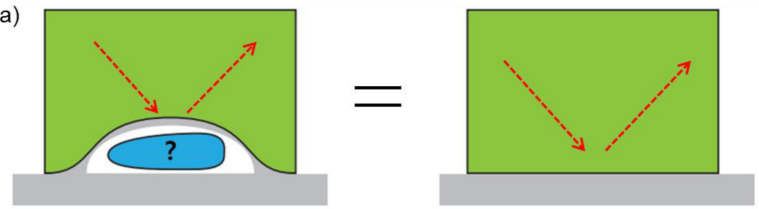

(b)

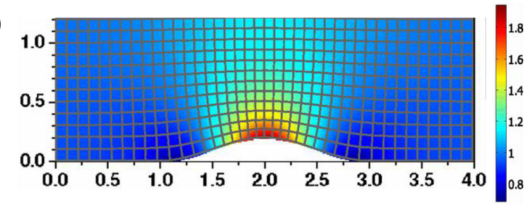

Fig. 8. (Color online) (a) Schematic of an invisibility carpet cloak. Normally light scatters from a bump on a planar surface. But, with a proper carpet cloak (left), light reflects from the bump smoothly as if it reflects from just a flat surface (right). (b) Spatial distribution of the normalized effective permittivity in an invisibility carpet cloak. Reprinted from Ref. [41] with permission. Quasiconformal mapping is used, as indicated by curved grid lines. Grid lines are orthogonal at each crossing point.

값으로 고정할 수 있다. Figure 7에 나온 구조는 $8.5 \mathrm{GHz}$ (파장으로는 $3.5 \mathrm{~cm}$ )에서 동작하는데, 각 $\mathrm{SRR}$ 의 크기는 $3 \mathrm{~mm}$ 정도로 입사 파장의 $1 / 10$ 보다 작다. 이 실험에서 는 금속 기둥을 투명망토 중앙에 넣어서 투명망토가 산 란에 미치는 영향을 측정했고, 투명망토가 없는 경우와 산란 정도를 비교했다. 이 실험을 통해 주어진 구조가 마 이크로파 투명망토로 동작함을 확인할 수 있었다.

이 연구는 투명망토의 구현 가능성을 보여주는 중요 한 연구 성과이나 여러 문제들도 존재한다. 우선 공명구 조를 이용하기 때문에 투명망토가 동작하는 주파수 대 역폭이 매우 적다. 또 물질상수에 비등방성이나 큰 유전 율/투과율을 요구하는 극한 구조는 가시광선 영역대에 서는 구현하기 매우 힘들다. 그리고 SRR 구조는 가시광 선 같은 아주 높은 주파수 영역대에서는 자기공명 특성 을 잃어버림이 알려져 있다 [34]. 하지만 이러한 문제들 을 해결하고 보다 실용적인 투명망토 구조를 개발하기 위한 다양한 노력들이 진행되어 왔다 [35-40]. 이를 위해 복잡한 물질상수 분포를 단순화하려는 연구들이 꾸준히 진행되어 왔다. 이는 새로운 제작 기술 및 신소재의 개 발과 맞물려 더욱 발전할 것이다.

특히 가시광선 근처에서 등방성 유전체 물질을 사용하 는 광대역 투명망토 기술에 대한 연구가 최근에 진행되 어 왔다. Figure 8(a)는 quasi-conformal mapping $(\mathrm{QCM})$ 을 이용한 투명카펫의 동작 원리를 보여준다 [41]. 빛의 투과가 아니라 빛의 반사 특성을 평면에서 조절하기 때 문에 '카펫'이라는 용어가 쓰인다. 이전의 투명망토에 비 해 완벽하다고 할 수는 없으나 물질상수에 대한 조건들 은 훨씬 완화할 수 있다. QCM에서는 변환된 격자 셀 라
인들이 서로 직각을 이루므로 비등방성 물질상수에 대 한 필요성을 획기적으로 줄일 수 있었다 (Fig. 8(b)). 비 등방성 물질상수를 구현할 필요가 없으므로 변환광학 구 조가 간단해진다. 또 $\mathrm{QCM}$ 기법을 이용하면 열저항이 높 은 금속 메타물질이 아닌 굴절률이 큰 유전체 (가령 반 도체) 물질로도 투명카펫을 구현하는 것이 가능하게 되 었다. 처음에는 마이크로파 영역에서 이 개념이 실험으 로 증명되었고 [42] 곧 이어 가시광선 근처 영역대로 확 장되었다 [43]. 특히 유전체를 이용한 투명카펫이 가시 광선 및 근적외선 영역에서 구현되었다 [44-47]. 또 투 명카펫은 보통 2 차원 상의 도파로 구조로 만들어졌으나, 3 차원 구조로 제작되기도 하였다 [43].

\section{IV. 변환광학의 최신 연구 주제들}

변환광학은 투명망토뿐 아니라 다른 여러 연구 주제 들에도 적용되고 있다. 변환광학 연구의 다른 재미있는 예로 광 블랙홀을 들 수 있다 [48-50]. 투명망토처럼 구 형이나 원통형의 껍질을 만들고 물질상수 분포를 조절 하면 들어오는 빛이 중심부로 휘감기며 끌려 오도록 할 수 있다. 이는 마치 블랙홀에 물체가 끌려가는 것과 비 슷하여 광 블랙홀이라고 부르기도 한다. 이 광 블랙홀 은 광대역 (broadband), 전방향 (omni-directional) 흡수 체로 쓰일 수 있다. 또한 천체 물리학 연구를 실험실 테 이블 위에서 해 볼 수 있다는 장점도 있다. 이외에도 변 환광학 개념을 적용하여 실제 물체와 다른 모습을 갖는 광학적 환영 (illusion)을 만드는 것도 가능하며, 이를 환 영광학 (illusion optics)이라는 이름으로 연구하고 있다 $[51,52]$.

또한 변환광학을 이용하여 새로운 형태의 광 집속체 (light concentrator)를 만들 수 있다 [53]. 기존의 렌즈 같 은 광학 기구와 달리 물질상수의 분포를 조절하여 삼각 형, 하트 모양, 찌그러진 구형 등 임의의 형태를 갖는 광 집속체를 만드는 것이 가능하다. 이외에도 변환광학을 이용한 새로운 광소자들에 대한 연구가 진행되고 있다. 물질 상수를 조절하여 뛰어난 성능을 갖는 beam shifter, beam splitter, beam rotator, waveguide bender 등을 디 자인 할 수 있다 [11-20].

변황광학은 광통신에 필요한 광소자에도 응용될 수 있 다. 가령 Fig. 9는 변환광학을 이용한 fiber-to-waveguide coupler를 보여준다 [54]. 광통신에서는 광섬유와 도파로 사이에 효율적인 광연결이 중요하나, 이 둘 사이에 크기 차이 및 정렬 문제로 효율적이고 안정적인 소자를 만드 는데 어려움이 있었다. 큰 모드 크기를 가지는 광섬유와 


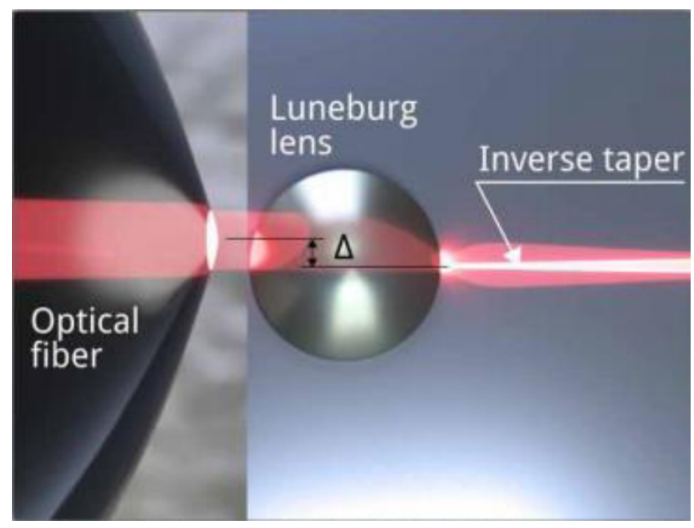

Fig. 9. (Color online) Preliminary demonstrations on transformation optics based integrated optical components (Fiber-to-waveguide coupler using a Luneburg lens). It can provide improved alignment tolerance, which is important for efficient communication networks. Reprinted from Ref. [54] with permission.

아주 작은 모드 크기를 가지는 광도파로 사이의 연결을 위해 현재는 inverse taper 등을 이용하나, taper 길이나 정렬 등의 문제점들이 있었다. Figure 9에서는 Luneburg 렌즈를 이용한 광연결 소자를 보여준다. Luneburg 렌즈 는 수차(aberration)가 없는 구형렌즈이다. 초점은 원주 상에 놓이게 되며, 들어오는 모든 광선들은 자연스럽게 휘어져서 원주 상의 이 점에 수차 없이 모이게 된다 [55]. Luneburg 렌즈는 회전 대칭을 갖는 굴절률 분포를 갖는 다: $n^{2}=n_{0}^{2}\left(2-r^{2}\right)$. 여기서 $r$ 은 중심부에서 방사방향으 로의 표준화된 (normalized) 거리이다. 또 $n_{0}$ 는 렌즈 표 면에서 배경 굴절률 (background medium index)과 같은 값을 갖도록 정한다. 이 변환광학 소자는 taper 구조보 다 더 유연하고 효율적인 광연결을 가능하도록 한다. 따 라서 앞으로 광통신에서 중요하게 쓰일 수 있는 가능성 을 갖는다.

맥스웰 방정식에서 나타나는 form-invariance 특성과 비슷한 좌표변환 특성을 갖는다면, 변환광학의 개념을 다른 파동 시스템에도 적용할 수 있다. 가령 탄성파 [56$58]$ 나 음파 [59,60]에 대한 투명망토를 만드는 것이 가능 하며 이를 실제로 구현하는 연구들이 많이 진행되었다. 음파의 경우 빛보다 파장이 더 길어서 음파 투명망토는 제작이 더 용이하다. 최근에는 $3 \mathrm{D}$ 프린터를 이용하여 음 파 투명망토를 제작하기도 한다. 이는 층간 소음을 없애 주는 방음재료 등에 응용될 수 있다. 또한 지진파에 대 한 투명망토를 구현하는 것도 흥미로운 연구 주제이다 [61]. 원전과 같이 중요한 시설은 지진과 같은 재난에 취 약할 수 있다. 따라서 원전을 둘러싸는 투명망토 시설을 제작하면 지진파가 원전과 같은 중요한 시설을 피해 가 도록 할 수 있다 (Fig. 10). 최근에는 또 변환광학을 유체

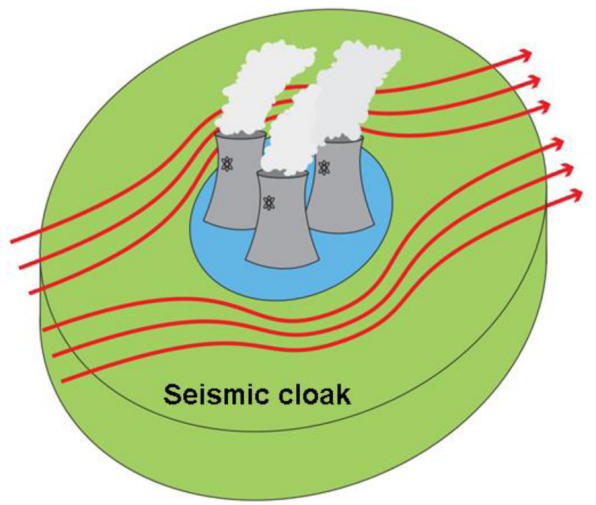

Fig. 10. (Color online) Schematic of a seismic wave invisibility cloak. The incident seismic wave bends around the central building (e.g., a nuclear power plant) and we can minimize earthquake damage, thanks to the invisibility cloak.

[62], 열 [63], 물질파 [64]에 적용하는 연구도 이루어지고 있다. 또한 공간상에서 빛이나 전자기파의 흐름을 조절 하는 것뿐 아니라 시간 상에서 조절하는 시간 투명망토 (temporal cloak)에 대한 연구도 진행되고 있다 $[65,66]$.

\section{V. 결론 및 전망}

이 총설논문에서는 변환광학의 개념을 소개하고 수학 적 기초를 설명하였다. 특히 투명망토를 구현하기 위한 물질상수 분포를 유도하고 실험으로 구현한 예들을 알 아 보았다. 또한 변환광학을 이용한 다른 응용과 광학소 자들을 소개하고 최신 연구동향을 살펴 보았다. 변환광 학은 많은 새로운 가능성을 제시해 주나, 복잡한 물질상 수 분포를 구현하기 어렵다는 단점도 있다. 따라서 변환 광학 분야는 나노 공정 기술의 발전과 맞물려 발전할 것 이다. 새로운 제작 기술과 신소재의 등장은 이 분야의 발 전에 크게 공헌할 것이다. 또 좀 더 간단한 물질상수 분 포를 찾는 이론 연구들도 계속될 것이며, 변환광학의 새 로운 응용분야를 찾는 노력도 계속될 것이다. 이를 통해 이전에는 상상으로만 가능했던 일들이 미래에는 현실이 되어 우리 눈 앞에 펼쳐질 수 있기를 기대해 본다.

\section{감사의 글}

본 논문은 2014년도 정부 (미래창조과학부)의 재원으 로 한국연구재단의 지원을 받아 수행된 연구이다 (No. 2008-0061893). 


\section{REFERENCES}

[1] J. B. Pendry, D. Schurig and D. R. Smith, Science 312, 1780 (2006).

[2] U. Leonhardt, Science 312,1777 (2006).

[3] D. Schurig, J. B. Pendry and D. R. Smith, Opt. Express 14, 9794 (2006).

[4] U. Leonhardt and T. G. Philbin, Prog. Opt. 53, 69 (2009).

[5] U. Leonhardt and T. G. Philbin, Geometry and Light: The Science of Invisibility (Dover Publications, New York, 2010).

[6] D.-H. Kwon and D. H. Werner, IEEE Antennas Propagat. Mag. 52, 24 (2010).

[7] H. Y. Chen, C. T. Chan and P. Sheng, Nature Mater. 9, 387 (2010).

[8] Y. Liu and X. Zhang, Nanoscale 4, 5277 (2012).

[9] J. B. Pendry, A. Aubry, D. R. Smith and S. A. Maier, Science 337, 549 (2012).

[10] R. Schittny, M. Kadic, T. Buckmann and M. Wegener, Science 345, 427 (2014).

[11] D. R. Roberts, M. Rahm, J. B. Pendry and D. R. Smith, Appl. Phys. Lett. 93, 251111 (2008).

[12] D. H. Kwon and D. H. Werner, New J. Phys. 10, 115023 (2008).

[13] N. I. Landy and W. J. Padilla, Opt. Express 17, 14872 (2009).

[14] H. Y. Chen, B. Hou, S. Y. Chen, X. Y. Ao and W. J. Wen et al., Phys. Rev. Lett. 102, 183903 (2009).

[15] N. Kundtz and D. R. Smith, Nat. Mater. 9, 129 (2010).

[16] H. F. Ma and T. J. Cui, Nat. Commun. 1, 124 (2010).

[17] T. Zentgraf, J. Valentine, N. Tapia, J. S. Li and X. Zhang, Adv. Mater. 22, 256 (2010).

[18] A. Aubry, D. Y. Lei, A. I. Fernandez-Dominguez, Y. Sonnefraud and S. A. Maier et al., Nano Lett. 10, 2574 (2010).

[19] A. Vakil and N. Engheta, Science 332, 1291 (2011).

[20] C. Navau, J. Prat-Camps, O. Romero-Isart, J. I. Cirac and A. Sanchez, Phys. Rev. Lett. 112, 253901 (2014).

[21] E. J. Post, Formal Structure of Electromagnetics: General Covariance and Electromagnetics (Interscience, New York, 1962).
[22] M. Lax and D. F. Nelson, Phys. Rev. B 13, 1777 (1976).

[23] A. J. Ward and J. B. Pendry, J. Mod. Opt. 43, 773 (1996).

[24] D. Schurig, J. J. Mock, B. J. Justice, S. A. Cummer and J. B. Pendry et al., Science 314, 977 (2006).

[25] J. D. Joannopoulos, R. D. Meade, S. G. Johnson and J. N. Winn, Photonic Crystals: Molding the Flow of Light, 2nd ed. (Princeton University Press, 2009).

[26] D. R. Smith, J. B. Pendry and M. C. K. Wiltshire, Science 305, 788 (2004).

[27] W. S. Cai and V. M. Shalaev, Optical Metamaterials: Fundamentals and Applications (Springer, New York, 2009).

[28] T. J. Cui, D. R. Smith and R. P. Liu, Metamaterials: Theory, Design, and Applications (Springer, 2009).

[29] Y. M. Liu and X. Zhang, Chem. Soc. Rev. 40, 2494 (2011).

[30] C. M. Soukoulis and M. Wegener, Nat. Photonics 5, 523 (2011).

[31] W. L. Barnes, A. Dereux and T. W. Ebbesen, Nature 424, 824 (2003).

[32] J. A. Schuller, E. S. Barnard, W. S. Cai, Y. C. Jun and J. S. White et al., Nat. Mater. 9, 193 (2010).

[33] J. B. Pendry, A. J. Holden, D. J. Robbins and W. J. Stewart, IEEE Trans. Microw. Theory. Tech. 47, 2075 (1999).

[34] J. Zhou, Th. Koschny, M. Kafesaki, E. N. Economou and J. B. Pendry et al., Phys. Rev. Lett. 95, 223902 (2005).

[35] W. S. Cai, U. K. Chettiar, A. V. Kildishev and V. M. Shalaev, Nat. Photonics 1, 224 (2007).

[36] U. Leonhardt and T. Tyc, Science 323, 110 (2009).

[37] J. P. Turpin, A. T. Massoud, Z. H. Jiang, P. L. Werner and D. H. Werner, Opt. Express 18, 244 (2010).

[38] M. Schmiele, V. S. Varma, C. Rockstuhl and F. Lederer, Phys. Rev. A 81, 033837 (2010).

[39] K. Yao and X. Y. Jiang, J. Opt. Soc. Am. B 28, 1037 (2011).

[40] N. Landy and D. R. Smith, Nat. Mater. 12, 25 (2013).

[41] J. S. Li and J. B. Pendry, Phys. Rev. Lett. 101, 203901 (2008). 
[42] R. Liu, C. Ji, J. J. Mock, J. Y. Chin and T. J. Cui et al., Science 323, 366 (2009).

[43] T. Ergin, N. Stenger, P. Brenner, J. B. Pendry and M. Wegener, Science 328, 337 (2010).

[44] J. Valentine, J. Li, T. Zentgraf, G. Bartal and X. Zhang, Nat. Mater. 7, 568 (2009).

[45] L. H. Gabrielli, J. Cardenas, C. B. Poitras and M. Lipson, Nat. Photonics 43, 461 (2009).

[46] J. H. Lee, J. Blair, V. A. Tamma, Q. Wu and S. J. Rhee et al., Opt. Express 17, 12922 (2009).

[47] M. Gharghi, C. Gladden, T. Zentgraf, Y. Liu and X. Yin et al., Nano Lett. 11, 2825 (2011).

[48] E. E. Narimanov and A. V. Kildishev, Appl. Phys. Lett. 95, 041106 (2009).

[49] D. A. Genov, S. Zhang and X. Zhang, Nat. Phys. 5, 687 (2009).

[50] C. Sheng, H. Liu, Y. Wang, S. N. Zhu and D. A. Genov, Nat. Photonics 7, 902 (2013).

[51] Y. Lai, J. Ng, H. Y. Chen, D. Z. Han and J. J. Xiao et al., Phys. Rev. Lett. 102, 253902 (2009).

[52] C. Li, X. Meng, X. Liu, F. Li and G. Y. Fang et al., Phys. Rev. Lett. 105, 233906 (2010).

[53] W. X. Jiang, T. J. Cui, Q. Cheng, J. Y. Chin and X. M. Yang et al., Appl. Phys. Lett. 92, 264101 (2008).

[54] L. H. Gabrielli and M. Lipson, Opt. Express 19, 20122 (2011).

[55] A. Di Falco, S. C. Kehr and U. Leonhardt, Opt. Express 19, 5156 (2011).

[56] G. W. Milton, M. Briane and J. R. Willis, New J. Phys. 8, 248 (2006).

[57] M. Farhat, S. Guenneau and S. Enoch, Phys. Rev. Lett. 103, 024301 (2009).

[58] N. Stenger, M. Wilhelm and M. Wegener, Phys. Rev. Lett. 108, 014301 (2012).
[59] H. Chen and C. T. Chan, Appl. Phys. Lett. 91, 183518 (2007).

[60] S. Zhang, C. G. Xia and N. Fang, Phys. Rev. Lett. 106, 024301 (2011).

[61] S. Brule, E. H. Javelaud, S. Enoch and S. Guenneau, Phys. Rev. Lett. 112, 133901 (2014).

[62] Y. A. Urzhumov and D. R. Smith, Phys. Rev. Lett. 107, 074501 (2011).

[63] R. Schittny, M. Kadic, S. Guenneau and M. Wegener, Phys. Rev. Lett. 110, 195901 (2013).

[64] S. Zhang, D. A. Genov, C. Sun and X. Zhang, Phys. Rev. Lett. 100, 123002 (2008).

[65] M. Fridman, A. Farsi, Y. Okawachi and A. L. Gaeta, Nature 481, 62 (2012).

[66] J. M. Lukens, D. E. Leaird and A. M. Weiner, Nature 498, 205 (2013).

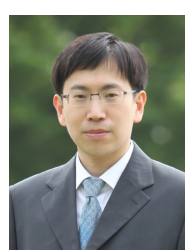

전영철 교수는 미국 스탠퍼드 대학 (Stanford University)에서 응용물리학으로 박사학위를 받은 후 미국 샌디아 국립 연구소 (Sandia National Laboratories) 박사후 연구원을 거쳐 현 재 인하대학교 물리학과 조교수로 재직 중이 다. 플라즈모닉스, 메타물질과 같은 나노광학 및 광전자소자 분야를 연구하고 있다.

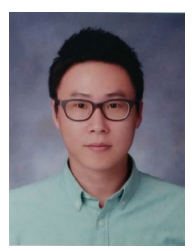

서인철 학생은 인하대학교 물리학과 학사과정 에 재학 중이며, 본교 대학원에 진학하여 나노 광학을 공부할 예정이다.

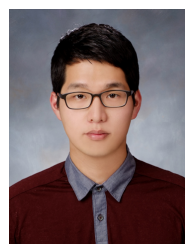

임성찬 학생은 인하대학교 물리학과 학사과정 에 재학 중이며, 본교 대학원에 진학하여 나노 광학을 공부할 예정이다. 